Table 2 Summary of clinical efficacy data for pediatric $r / r$ ALL therapies

\begin{tabular}{llll} 
& $\begin{array}{l}\text { Clolar (Evoltra (clofarabine); } \\
\text { Sanofi) }\end{array}$ & $\begin{array}{l}\text { Blincyto (blinatu- } \\
\text { momab; Amgen) }\end{array}$ & CTL019 \\
\hline Patients (N) & 61 & 70 & 68 \\
\hline$\geq 3$ prior regimens & $62 \%$ & $7 \%$ & $60 \%$ \\
\hline ORR & $20 \%$ & $39 \%$ & $83 \%$ \\
\hline Minimal residual disease negative & NA & $20 \%$ & $83 \%$ \\
\hline Median overall survival (OS) & 3 months & 7.5 months & 16.6 months \\
\hline 12-month OS & $20 \%$ & $40 \%$ & $79 \%$ \\
\hline Early mortality (within 30 days) & $25 \%$ & $7 \%$ & $3 \%$ \\
\hline
\end{tabular}

$r / r$, relapsed or refractory; NA, not available. Source: Novartis (Disclaimer: Because of differences in study designs, patient populations and other factors, cross-trial comparisons cannot be made.)

B-cell malignancies or is this a new paradigm for cancer in general?" asks Renjer Brentjens, medical oncologist at Memorial Sloan Kettering Cancer Center in New York and scientific co-founder of Juno Therapeutics. "It not a coincidence, I think, that everyone started targeting CD19." Finding other tumorassociated antigens that are not expressed on essential tissue is challenging. "This becomes particularly difficult in the area of solid tumor malignancies," Brentjens says. Patterns of antigen expression on solid tumor cells are more heterogeneous than those on hematological cancer cells, he says. "Immune escape is extremely possible," he says. The immunosuppressive 'scaffold' that solid tumors erect further complicates the picture. "I do think the technology, as it stands right now-I may be wrong-is most likely going to be restricted to a select number of malignancies," he says. However, novel CAR-T architectures incorporating additional immunostimulatory features, as well as molecular safety switches, are already in early stages of development. A first CAR-T cell approval this year is likely to energize this research.

The pioneers who brought the technology to its present juncture deserve credit for keeping faith with the concept that the T-cell response is programmable, at least in the sense that the set of biological instructions encoded in an infusion of CAR-T cells can, when its technical specifications are properly defined and the clinical context in which it is deployed is properly understood, lead to dramatic outcomes. Young patients with relapsed or refractory B-cell ALL will be the first to benefit from this innovation; they're unlikely to be the last. "We need to pause and acknowledge the extraordinary amount of scientific learning that went into this event," Dranoff says.

Cormac Sheridan Dublin

\footnotetext{
66 "I talk about it at every turn, just like you talk about your kids hitting a home run and your daughter getting into law school." Representative Chris Collins (R-NY) urged his US House of Representatives colleagues to invest in Australian biotech Innate Immunotherapeutics', which later, in June, lost $96 \%$ of its value when its sole asset (myeloid immune modulator MIS416) failed in a phase $2 \mathrm{~b}$ trial. (STAT, 27 June 2017)

"Typically with the launch of a new product, I would be in a 'fast and furious, immediate revenue up and to the right as fast as you can' mode. This is not the place to employ that strategy." Kite Chief Commercial Officer Shawn Tomasello addresses the difficult choices that have to be made when working with CAR-T therapies.

(Bloomberg, 7 July 2017)
}

\section{LifeArc splashes out, fuelled by Keytruda}

LifeArc, the rebranded MRC Technology, is set to fund $£ 500$ (\$652) million of medical research projects over five years under a plan announced June 15. LifeArc is benefiting from royalties owing from its development work on Merck's immuno-oncology drug Keytruda (pembrolizumab). In 2006, MRC Technology scientists at its Therapeutic Antibody Group, humanized the antibody for Organon Biosciences (Organon was subsequently acquired by ScheringPlough, which later merged into Kenilworth, New Jersey-based Merck). Last year, MRC Technology partially monetized that royalty stream to the tune of $£ 115$ ( $\$ 150)$ million. "With the Keytruda money coming in, it was time for us to be totally independent," says LifeArc's head of innovation and initiatives, David Pardoe. MRC Technology's work has also helped develop three approved drugs: Actemra (tocilizumab, for rheumatoid arthritis, from Genentech), Tysabri (natalizumab, for multiple sclerosis, from Biogen) and Entyvio (vedolizumab, for ulcerative colitis, from Takeda's Millennium Pharmaceuticals), and a test for antimicrobial resistance.

The name change to LifeArc and its revamped funding plan reflect London-based charity's evolution. It came into being in 2000 as the technology transfer arm of the UK's Medical Research Council (MRC). Since then, it has expanded the range of its activities to include over 50 organizations in addition to the MRC. With the new funding, the not-for-profit organization will place special emphasis on supporting earlystage work in antimicrobials, neuroscience, personalized medicine in oncology and respiratory diseases.

Pardoe adds that LifeArc's strong relationships with charities across the UK, the EU and the US place it in "a fantastic position to be able to fully understand the patient advocacy side of things." LifeArc will organize projects informed by patient need and translate them into treatments pharma can then commercialize. "We are in a very unusual situation," Pardoe says-trusted by charities, patient advocacy groups, by governments, by pharma and by academics. Future plans include launching two new fundsthe Philanthropic and Seed funds-that will invest £30 (\$39) million into academic research and early-stage therapeutics and biological research. It recently invested $£ 20(\$ 26)$ million in a new drug discovery complex in Stevenage and a diagnostics development center in Edinburgh.

On July 14, UK Health Minister James O'Shaughnessy announced new government funding of up to $£ 86$ ( $\$ 112$ million), in another move aimed at accelerating UK patients' access to medical innovation and technology. The investment package includes $£ 39$ ( $\$ 51$ ) million to assess the new technologies' benefits and to support their clinical uptake; a $£ 35$ (\$46) million "Digital Health Technology Catalyst" for innovators; up to $£ 6$ (\$7.8) million over the next three years to help small and medium-sized enterprises develop real-world evidence showing the benefit of their technologies; and $£ 6$ million to help National Health Service organizations integrate new technologies into everyday practices. 